\title{
Subjective Opinions of Patients About Step-by- Step Cataract Surgery Preparation
}

This article was published in the following Dove Press journal:

Clinical Ophthalmology

\author{
Iwona Obuchowska (iD \\ Dorota Ługowska \\ Zofia Mariak (iD \\ Joanna Konopińska
}

Department of Ophthalmology, Medical University of Bialystok, Bialystok, 15-276, Poland
Correspondence: Iwona Obuchowska Department of Ophthalmology, Medica University of Białystok, M. SklodowskaCurie 24A STR, Białystok, 15-276, Poland Tel +48-857468372

Email iwonaobu@wp.pl
Purpose: We analyzed the subjective feelings and opinions of patients regarding modified cataract phacoemulsification procedures.

Patients and Methods: A consecutive case series of patients undergoing phacoemulsification of cataracts, who completed questionnaires designed by the authors to evaluate their subjective opinions about hospital admission, medical examination, and intraoperative procedures carried out at the operating theater.

Results: Two hundred patients ( 82 men and 118 women) were included in the study. Subjects aged $\geq 65$ years more often than younger respondents presented negative opinions about hospital admission procedures ( $15 \%$ vs. $2.5 \%, \mathrm{p}=0.032)$ and were less satisfied with physicians' explanations about the matter of phacoemulsification $(71.3 \%$ vs. $92.5 \%$, $\mathrm{p}=0.004)$, type of artificial lens to be implanted $(43.8 \%$ vs. $85 \%, \mathrm{p}<0.001)$, and potential complications $(69.4 \%$ vs. $95 \%, \mathrm{p}<0.001)$. The most unpleasant intraoperative experiences included venipuncture (35.5\%), artificial lens implantation $(30.5 \%)$, and peeling off of a sterile surgical drape (24\%).

Conclusion: Persons aged $\geq 65$ years presented with negative opinions about routine procedures related to phacoemulsification. Older age seems to be associated with less tolerance to time-consuming bureaucratic procedures and a lesser understanding of the specific stages of the surgery. Older patients should be notified in advance about all routine procedures to be carried out and provided with a rationale for these activities.

Trial Registration: The study was registered on clinicaltrials. gov (NCT04327856).

Keywords: phacoemulsification of cataract, patients subjective experiences, quality of life

\section{Introduction}

Cataract is a leading cause of blindness worldwide, and its surgical removal is one of the most common procedures performed nowadays. Phacoemulsification is most often a one-day procedure performed under topical anesthesia, with full logical contact and cooperation of the patient.

Since phacoemulsification has been a subject of extensive research, the protocols for this procedure have been fully optimized from a technical perspective. However, the patient who is the benefactor of the procedure, and hence, patients' experiences during phacoemulsification are at least equally important as surgical outcomes of the surgery. Most of the currently available information on the emotions and expectations of patients undergoing phacoemulsification refers to the preoperative period. Most patients experience some anxiety before the procedure; they are afraid of the surgery itself and are concerned about potential postoperative loss or deterioration of vision. ${ }^{1-6}$ Research has shown that these concerns might be 
diminished if a good relationship is established between the patient and medical personnel. ${ }^{7,8}$ In addition, there are papers, which describe the subjective feelings of patients during the phacoemulsification procedure, such as the perception of pain, fear, visual and auditory sensation, and duration of the surgery. ${ }^{9-19}$ Comparative analysis of the subjective opinions of patients who underwent cataract surgery for one or both eyes demonstrated that the first procedure was associated with higher levels of stress and anxiety, whereas the second one was accompanied by more severe subjective pain. ${ }^{6,20-25}$

Patients operated for cataract usually expect that the surgery will enable them to achieve spectacle independence and normalization of visual acuity. ${ }^{26-34}$ Commonly, and most persons subjected to cataract surgeries are highly satisfied with the outcomes..$^{27,30,31,34,35}$ However, persons with higher preoperative expectations were shown to present with lower levels of postoperative satisfaction. Age and sex of operated patients seem to exert a substantial effect on expectations regarding the postoperative outcomes: older persons were shown to be less likely to expect complete spectacle independence after phacoemulsification. ${ }^{32-34,36}$ Similarly, male patients were satisfied with the outcomes of the procedure slightly more often than women. ${ }^{26,35}$ Finally, according to Nijkamp et al, ${ }^{36}$ a higher education level was associated with more realistic expectations with regard to the phacoemulsification outcome.

To the best of our knowledge, no sufficiently large study has analyzed how patients assess specific stages of cataract surgery. Although the same procedures are routinely repeated during each phacoemulsification, it is unlikely that all patients were equally satisfied with them. Thus, the surgery should not be considered fully optimized, and all its modifiable components, which the patients are least satisfied with, should be identified and improved or eliminated.

Given the lack of detailed knowledge, we decided to analyze patients' opinions about various aspects of preparation for cataract surgery and the procedure itself. We aimed to identify the procedures that the patients were least satisfied with, and as such, require some modification. We also verified whether the subjective opinions of patients were influenced by their sociodemographic characteristics. In our opinion, the results of this study provide the grounds for the development of new standards of care, and the creation of such standards would optimize periand intraoperative management of patients undergoing cataract surgeries, and thus, may improve their comfort of life.

\section{Patients and Methods}

The study was carried out with the approval of the Local Bioethics Committee of the Medical University of Bialystok and followed the ethical standards as laid down in the 1964 Declaration of Helsinki and its later amendments or comparable ethical standards. All subjects provided written, fully informed consent for the examination and use of their clinical data for publication.

Two hundred consecutive patients undergoing routine phacoemulsification of cataract, for the first eye, under topical anesthesia as the one-day procedure at the Department of Ophthalmology, Medical University of Bialystok, between March and June 2020 were included in the study. Patients who did not give their consent to participate, as well as those with severe deafness, dementia, or a mental disorder were excluded from the study. Patients undergoing complicated cataract surgery or multiple procedures during a single operation were also excluded.

We designed a detailed survey on the patients' experiences and opinions regarding hospital admission procedures, preparation for phacoemulsification, and the procedure itself. The questionnaire consisted of closedended single-answer and multiple-choice questions. The patients received the survey directly after the surgery in the postoperative recovery room and were allowed to use the assistance of another person to read, understand, and complete the questionnaire. A specimen of the questionnaire is included in the Supplement (Suppl 1). Each patient could withdraw from the study at any time.

In all patients' consent for the operation was obtained by a surgeon who performed it, after a detailed information of the procedure, its aim and possible complications, following the standard script.

\section{Statistical Analysis}

The data obtained from the survey were analyzed and verified using $R$ statistical software, version 3.5.4. The answers to most questions were qualitative, and as such, were summarized as numbers and percentages. The normal distribution of quantitative variables was verified using the Kolmogorov-Smirnov test. As the data were not distributed normally, their statistical characteristics were presented as numbers, arithmetic means, standard deviations, and medians. 
Responding to some questions, the patients could choose more than one answer. When a statistically significant between-group difference was found in the distribution of answers to such questions, a series of post-hoc chisquared tests were carried out to identify the source of the difference.

Considering the quantitative nature of the data, lack of normal distribution, and the lack of between-group equivalence, non-parametric tests were used, namely, MannWhitney $U$-test and Kruskal-Wallis for comparisons between two or more groups, respectively. The results were considered statistically significant if the p-value was less than 0.05 .

\section{Results}

A total of 200 consecutive patients ( 82 men and 118 women) aged 51-93 years were enrolled in this study. Mean age of the study group was $75.0 \pm 12.3$ years, with mean ages for male and female patients of $73.5 \pm 11.9$ and $76.2 \pm 11.2$ years, respectively. The sociodemographic characteristics of the study participants are shown in Table 1.

The following groups were identified for the purpose of statistical analysis and compared: 1) men $(n=118)$ vs. women $(\mathrm{n}=82) ; 2)$ persons aged $<65$ years $(\mathrm{n}=40)$ vs. $\geq 65$ years of age ( $\mathrm{n}=160$ ); ( 65 years is the usual retirement age); and 3) primary or vocational school graduates $(\mathrm{n}=90)$ vs. secondary school or university graduates $(n=110)$.

\section{Hospital Admission Procedures}

Hospital admission procedures were assessed positively by $87 \%$ of the respondents. The lowest proportion of satisfied respondents (approximately 84\%) was observed among

Table I Sociodemographic Characteristics of the Studied Group of Patients

\begin{tabular}{|l|l|c|c|}
\hline \multicolumn{2}{|l|}{ Sociodemographic Characteristics } & Number & Percent \\
\hline Sex & Female & 118 & $59 \%$ \\
& Male & 82 & $41 \%$ \\
\hline Age (years) & $<65$ & 40 & $20 \%$ \\
& $\geq 65$ & 160 & $80 \%$ \\
\hline \multirow{2}{*}{ Education } & Primary & 39 & $19.5 \%$ \\
& Vocational & 51 & $25.5 \%$ \\
& Secondary & 79 & $39.5 \%$ \\
& Higher & 31 & $15.5 \%$ \\
\hline \multirow{2}{*}{ Current professional activity } & Employed & 32 & $16.0 \%$ \\
& Pensioner & 168 & $84.0 \%$ \\
\hline
\end{tabular}

women, persons with primary or vocational education, and patients aged $\geq 65$ years. However, a statistically significant difference in the percentage of satisfied respondents was found solely when the results were stratified according to age. Patients aged $\geq 65$ years significantly more often than younger respondents declared that hospital admission procedures were inefficient, lasted too long, and/or were associated with stress $(15 \%$ vs. $2.5 \%$, $\mathrm{p}=0.032$ ).

\section{Preparation for the Surgery by a Nurse}

Most respondents (87.9\%) assessed the positive admission interviews conducted by nurses. However, $6.7 \%$ and $4.3 \%$ of the patients, respectively, stated that the interview lasted too long or was too short, and according to $1.1 \%$, the nurse did not offer them enough support at this stage. No significant associations were observed between the evaluation of the admission interview and respondents' age, sex, and education.

Up to $72 \%$ of the respondents had some negative experiences, such as burning sensation, excruciating pain, or tearing, during the preoperative application of eye drops. Before phacoemulsification, each patient received topical anesthetic eye drops and pupil-dilating eye drops, either applied several times. No statistically significant differences in the experiences associated with eye drop application were found when the results were stratified according to age, sex, or education. However, when the patients were asked whether the preoperative application of eye drops at such a large volume was essential, the proportion of positive responses among persons aged $<65$ years turned out to be significantly higher than among those aged $\geq 65$ years $(p=0.044)$. Similarly, patients $\geq 65$ years of age were less often satisfied with the way the nurse explained the reason behind applying such a large volume of eye drops to the operated eye $(62.5 \%$ vs. $82.5 \%$, $\mathrm{p}=0.027)$. In addition, men tended to be less satisfied than women with the nurse's explanation in that matter, but this between-group difference did not reach the threshold of statistical significance $(\mathrm{p}=0.058)$.

\section{History Taking and Preoperative Examination by a Physician}

While most patients $(89.5 \%)$ were satisfied with the preoperative examination by a physician, some found this procedure exhaustive, burdensome, and too long (6.3\%), or inversely, too short and superficial (4.2\%). 
Compared with respondents aged $\geq 65$ years, those aged $<65$ years were more often satisfied with the physician's explanations about the nature of phacoemulsification $(92.5 \%$ vs. $71.3 \%, p=0.004)$, type of artificial lens, and purpose of its implantation during the procedure $(85 \%$ vs. $43.8 \%, \mathrm{p}<0.001)$, and potential complications $(95 \%$ vs. $69.4 \%, \mathrm{p}<0.001)$. Information provided by the physician was more comprehensible for patients with secondary or higher education than for primary or vocational school graduates, and significant between-group differences were found for the explanations about the nature of phacoemulsification $(84.5 \%$ vs. $64.4 \%, \mathrm{p}=0.002)$ and information about potential complications of this procedure (88.2\% vs. $67.7 \%, p=0.01$ ). Patients aged $\geq 65$ years and those with primary or vocational education typically complained that the explanations were too complicated and/or too short, the physician was using medical jargon, did not allocate enough time for questions, and patronized them. No significant associations were found between the preoperative examinations and sex.

\section{Activities Undertaken by a Nurse Anesthetist at the Operating Theater}

The list of respondent-evaluated medical procedures carried out by a nurse anesthetist at the operating theater included venipuncture, insertion of the venous catheter, measurement of oxygen saturation, application of sphygmomanometer cuff, and blood pressure measurement. Many of these activities are associated with pain and other unpleasant experiences. Up to $72 \%$ of the respondents were satisfied with the way the nurse anesthetist informed them about the intention to carry out the procedures mentioned above and the nature thereof. Compared with patients $<65$ years of age, those aged $\geq 65$ years significantly more often complained that they were not informed in advance about the nurse anesthetist's intention to carry out some specific procedures, which created stress when the procedure was eventually introduced ( $33.1 \%$ vs. $7.5 \%, \mathrm{p}=0.008)$.

\section{The Most Unpleasant Intraoperative Experiences}

The most unpleasant experience during cataract surgery was venipuncture $(n=71,35.5 \%)$, followed by artificial lens implantation $(\mathrm{n}=61,30.5 \%)$ and peeling off of a sterile surgical drape after the procedure $(n=48,24 \%)$. Male patients found venipuncture the most unpleasant experience significantly more often than female patients
( $47.6 \%$ vs. $27.1 \%, p=0.010$ ), whereas women considered peeling off of a sterile surgical drape after the procedure as the most unpleasant experience significantly more often than men $(28.8 \%$ vs. $17.1 \%, \mathrm{p}=0.010)$. Respondents $<65$ years of age considered venipuncture to be the most unpleasant experience significantly more often than patients $\geq 65$ years of age $(52.5 \%$ vs. $31.3 \%$, p=0.008) (Table 2$)$.

\section{Comprehensibility of Orders Received from Medical Personnel at the Operating} Theater and Cooperation with Personnel

While most respondents $(\mathrm{n}=186,93 \%)$ assessed their cooperation with medical personnel at the operating theater positively, $7 \%(\mathrm{n}=14)$ had some reservations in this matter. The most common dissatisfaction was caused by giving orders with too quiet or raised voice, shouting at patients, or hurrying them up. No statistically significant relationships were observed between age, sex, education of the respondents, and their subjective opinions about the quality of cooperation with the surgical team.

Considering the groups identified based on sociographic variables, negative opinions regarding hospital admission, preparation for cataract surgery, and the procedure itself were most often presented by respondents $\geq 65$ years of age (Table 3). Aside from age, no other sociodemographic variables significantly influenced the assessment of the analyzed procedures. Education exerted a significant effect on understanding the matter of cataract surgery and its potential complications. Finally, female and male patients, as well as younger and older respondents, differed significantly in terms of their opinions about the most unpleasant intraoperative experiences.

\section{Discussion}

The aim of this study was to analyze the subjective feelings and opinions of patients regarding the procedures associated with phacoemulsification cataract. The patients were asked about their opinions regarding some specific, modifiable aspects of preparation for surgery, and hence, could be improved if assessed negatively by them. While some previous studies analyzed subjective experiences of patients before and during cataract surgery, most of them focused on preoperative anxiety, pain, or visual sensations during the operation. ${ }^{2,5,6,9-25}$ To the best of our knowledge, none of the previous studies aimed to identify the least positive components of the phacoemulsification procedure. 
Table 2 The Most Unpleasant Sensations During the Cataract Surgery

\begin{tabular}{|c|c|c|c|c|c|}
\hline Feature & $\mathbf{n}$ & $\%$ & $\mathbf{n}$ & $\%$ & $\mathbf{P}$ \\
\hline & \multicolumn{4}{|c|}{ Płeć } & \\
\hline & \multicolumn{2}{|c|}{ Women $(n=118)$} & \multicolumn{2}{|c|}{ Men $(n=82)$} & \\
\hline Intravenous cannulation & 32 & $27.1^{\mathrm{a}}$ & 39 & $47.6^{\mathrm{a}}$ & \\
\hline Inflating a sleeve of a manometer & 3 & 2.6 & I & 1.2 & \\
\hline Corneal cut & 10 & 8.5 & 4 & 4.9 & \\
\hline Artificial lens implantation & 38 & 32.2 & 23 & 28.0 & \\
\hline Peeling of sterile surgical drape & 34 & $28.8^{\mathrm{b}}$ & 14 & $17.1^{\mathrm{b}}$ & \\
\hline \multirow[t]{3}{*}{ None } & 1 & 0.8 & 1 & 1.2 & \\
\hline & \multicolumn{4}{|c|}{ Age } & \\
\hline & \multicolumn{2}{|c|}{$<65$ years $(n=40)$} & \multicolumn{2}{|c|}{$\geq 65$ years $(n=160)$} & \\
\hline Intravenous cannulation & 21 & $52.5^{c}$ & 50 & $31.3^{c}$ & \\
\hline Inflating a sleeve of a manometer & 1 & 2.5 & 3 & 1.9 & \\
\hline Corneal cut & 2 & 5.0 & 12 & 7.5 & \\
\hline Artificial lens implantation & 9 & 22.5 & 52 & 32.5 & \\
\hline Peeling of sterile surgical drape & 7 & 17.5 & $4 I$ & 25.6 & \\
\hline \multirow[t]{3}{*}{ None } & 0 & 0.0 & 2 & 1.2 & \\
\hline & \multicolumn{4}{|c|}{ Education } & \\
\hline & \multicolumn{2}{|c|}{ Primary/vocational $(n=90)$} & \multicolumn{2}{|c|}{ Secondary/higher $(n=110)$} & \\
\hline Intravenous cannulation & 32 & 35.6 & 39 & 35.4 & 0.086 \\
\hline Inflating a sleeve of a manometer & 1 & 1.1 & 3 & 2.7 & \\
\hline Corneal cut & 6 & 6.7 & 8 & 7.3 & \\
\hline Artificial lens implantation & 30 & 33.3 & 31 & 28.2 & \\
\hline Peeling of sterile surgical drape & 20 & 22.2 & 28 & 25.5 & \\
\hline None & I & 1.1 & I & 0.9 & \\
\hline
\end{tabular}

Note: Statistically significant differences in post-hoc test $\left({ }^{a} \mathrm{p}=0.010 ;{ }^{b} \mathrm{p}=0.010 ;{ }^{c} \mathrm{p}=0.008\right)$.

Hospital admission procedures were more often assessed negatively by patients aged $\geq 65$ years, who complained that the process took too long and was associated with unnecessary stress. Presumably, because of their age and related diseases, older patients might be less tolerant to time-consuming bureaucratic procedures associated with hospital admission.

Most respondents were highly satisfied with their contact with nurses who prepared them for surgery. Nevertheless, nearly three out of four respondents had some unpleasant experiences, such as burning, excruciating pain, and excessive tearing, during the application of eye drops before the procedure. Although many patients were aware that the application was necessary, a large proportion of them were not satisfied with the nurse's explanation of why eye drops had to be applied so frequently. Our experiences suggest that most patients could not remember the information they received a few weeks before phacoemulsification. A previous study showed that a few conversations with a nurse during the week preceding hospital admission might improve both patients' cooperation with medical personnel during the surgery and their satisfaction with the postoperative outcomes. ${ }^{37}$ The authors of that study emphasized that such conversations, during which, the nurse discusses eye anatomy, pathomechanism of cataract, the protocol of cataract surgery, preparation for the procedure, postoperative pain management and eye rehabilitation, might soothe negative emotions of patients during subsequent stages of phacoemulsification. ${ }^{37}$ The role of nurses in the education of patients with cataract was also highlighted by other authors. $^{38-40}$

In the case of our respondents, the biggest problem was the fact that the patients were not informed about nurse anesthetist activities in advance and often, they felt unpleasantly surprised when the nurse proceeded with an 
Table 3 Patients' Opinions on Routines Accompanying the Cataract Phacoemulsification Depending on Age (Closed-End Questions with Single Answer)

\begin{tabular}{|c|c|c|c|c|c|c|}
\hline \multicolumn{2}{|l|}{ Feature } & \multicolumn{2}{|c|}{$\begin{array}{l}<65 \text { Years } \\
(n=40)\end{array}$} & \multicolumn{2}{|c|}{$\begin{array}{l}\geq 65 \text { Years } \\
(n=160)\end{array}$} & \multirow{4}{*}{$\begin{array}{c}\mathbf{P} \\
0.018\end{array}$} \\
\hline \multirow[t]{3}{*}{ Whether admission to hospital went smoothly? } & Yes & 37 & 92.5 & 135 & 84.4 & \\
\hline & No & 1 & $2.5^{\mathrm{a}}$ & 24 & $15.0^{\mathrm{a}}$ & \\
\hline & Not sure & 2 & 5.0 & I & 0.6 & \\
\hline \multirow[t]{3}{*}{ Are you satisfied with the nursing interview? } & Yes & 35 & 87.5 & $|4|$ & 88.2 & 0.547 \\
\hline & No & 5 & 12.5 & 17 & 10.6 & \\
\hline & Not sure & 0 & 0.0 & 2 & 1.2 & \\
\hline \multirow{3}{*}{$\begin{array}{l}\text { Whether you have been satisfactorily explained about the necessity to put a lot of drops in } \\
\text { your eye before surgery? }\end{array}$} & Yes & 33 & $82.5^{\mathrm{b}}$ & 100 & $62.5^{\mathrm{b}}$ & 0.044 \\
\hline & No & 7 & 17.5 & 55 & 34.4 & \\
\hline & Not sure & 0 & 0.0 & 5 & 3.1 & \\
\hline \multirow[t]{3}{*}{ Whether you were satisfactorily explained what the cataract surgery is about? } & Yes & 37 & $92.5^{\mathrm{c}}$ & 114 & $71.3^{\mathrm{c}}$ & 0.016 \\
\hline & No & 3 & $7.5^{\mathrm{d}}$ & 39 & $24.4^{d}$ & \\
\hline & Not sure & 0 & 0.0 & 7 & 4.4 & \\
\hline \multirow[t]{3}{*}{ Whether the information on the artificial lens was clearly presented? } & Yes & 34 & 85.0 & 70 & 43.8 & $<0.001$ \\
\hline & No & 6 & 15.0 & 81 & 50.6 & \\
\hline & Not sure & 0 & 0.0 & 9 & 5.6 & \\
\hline \multirow[t]{3}{*}{ Whether the information about cataract surgery complications was clearly presented? } & Yes & 38 & $95.0^{\mathrm{e}}$ & 111 & $69.4^{\mathrm{e}}$ & 0.001 \\
\hline & No & 1 & 2.5 & 43 & 26.9 & \\
\hline & Not sure & I & 2.5 & 6 & 3.7 & \\
\hline \multirow[t]{3}{*}{ Has the anesthesiological nurse informed about the procedures performed? } & Yes & 35 & $87.5^{f}$ & 101 & $63.1^{\mathrm{f}}$ & 0.011 \\
\hline & No & 3 & $7.5^{g}$ & 53 & $33.1^{g}$ & \\
\hline & Not sure & 2 & 5.0 & 6 & 3.8 & \\
\hline \multirow[t]{3}{*}{ Did you understand the orders given by the medical staff in the operating theater? } & Yes & 37 & 92.5 & 151 & 94.4 & 0.710 \\
\hline & No & 3 & 7.5 & 9 & 5.6 & \\
\hline & Not sure & 0 & 0.0 & 0 & 0.0 & \\
\hline \multirow[t]{3}{*}{ Whether the cooperation in the operating theater with the medical staff was smooth? } & Yes & 37 & 92.5 & 150 & 93.8 & 0.685 \\
\hline & No & 3 & 7.5 & 8 & 5.0 & \\
\hline & Not sure & 0 & 0.0 & 2 & 1.2 & \\
\hline
\end{tabular}

Notes: Statistically significant differences in post-hoc test $\left({ }^{a} p=0.032 ;{ }^{b} p=0.027 ;{ }^{c} p=0.004 ;{ }^{d} p=0.017 ;{ }^{e} p<0.001 ;{ }^{f} p=0.003 ;{ }^{g} p=0.008\right)$.

activity, they did not expect. This problem was reported by up to one-third of patients aged $\geq 65$ years, the largest group of respondents. This implies that the patients were not familiar with the essential procedures to be undertaken prior to cataract surgery. The problem described above corresponds well with another aspect of cataract surgery assessed by our respondents, that is, the most unpleasant intraoperative experience. According to our respondents, the most unpleasant experience during cataract surgery was venipuncture $(35.5 \%)$, followed by the implantation of an artificial lens (30.5\%) and peeling off of a sterile surgical drape after the procedure (24\%). As stated by Rothschild et al, ${ }^{16}$ emotions experienced by patients subjected to phacoemulsification under topical anesthesia are not strong enough to blur their objective assessment of the situation. The patients can accurately, with only a small margin of error, estimate the duration of the procedure without checking the time on the clock. This implies that the patients' rating of an intraoperative experience as unpleasant should be considered an objective opinion. Surprisingly, one study showed that venipuncture was considered less painful and tolerated better when the patients were kept ignorant of the fact that their vein is going to be punctured. ${ }^{41}$ Moreover, the insertion of a smaller sized peripheral intravenous catheter did not result in a lower pain sensation. To prevent pain upon insertion of a peripheral intravenous catheter, an unsuccessful attempt must be avoided. ${ }^{42}$ This seems 
contradictory to our previous observation that the respondents preferred to be informed in advance about the activities undertaken by the nurse anesthetist. However, a more comprehensive analysis of the responses demonstrated that the activities that the patients preferred to be informed about included some specific procedures, such as the placement of pulse oximeter around the finger and pumping sphygmomanometer cuff during the surgery.

The proportion of women who considered peeling off of a sterile surgical drape after the procedure unpleasant was nearly twice as high as the proportion of male patients. The drapes are peeled off at the time medical personnel are already relaxed after completing the procedure, and hence, not infrequently less focused and acting in a hurry. However, as shown in the present study, this stage of phacoemulsification should not be neglected, as for some patients, it could be more harmful than the procedure itself.

This study had some limitations that need to be considered. The study was based solely on a self-reported questionnaire; hence, all collected opinions were subjective. Simultaneous analysis of patients' and nurses' and physicians' opinions would be an interesting approach to the problem in question. In addition, there were different surgeons who sought the patient's consent for surgery, and there might be a significant variable in their ability for providing information though it can have an impact for the subject subjective opinion. Another limitation of this study might be the selection of the respondents. To obtain a homogenous sample, we enrolled only patients who underwent surgery for the first eye. We are aware that a comparative analysis of the opinions of patients operated on for the first and the second eye would be an interesting approach. It would be interesting to verify whether experiences from the first surgery affected patients' opinions about the same procedures during the second surgery. It has already been shown that the second surgery is associated with different levels of anxiety and pain perception. Future study could access the enrollment of patients who underwent surgery twice, with a similar time interval between the first and second surgeries.

\section{Conclusions}

Persons aged $\geq 65$ years most often present with negative opinions about hospital admission procedures, preparation for phacoemulsification, and surgery itself. Older age seems to be associated with less tolerance to timeconsuming procedures and a lesser understanding of the specific stages of the surgery. Older patients should be notified in advance about all routine procedures to be carried out and provided with a rationale for these activities. Age and sex influence patients' opinions about the most unpleasant experiences during cataract surgery.

Based on our conclusions, we formulated the following recommendations to improve the patient experience for cataract surgery:

1. Introduction a special "time window" at the hospital's admission room, dedicated solely to persons admitted for one-day cataract surgery. During this time window, scheduled early in the morning, a larger number of personnel from the admission room were assigned to this task.

2. Providing each patient with a leaflet containing crucial information about admission for cataract surgery along with a telephone number, they could call in the case of additional questions or concerns.

3. Briefing the patient once again about the most critical aspects of the procedure shortly after admission. Moreover, before each stage of the surgery, the patient was reminded of the key activities to be undertaken and their objectives.

4. Replacing preoperative application of eye drops with an intraoperative intracameral injection of a solution containing two mydriatics and a local anesthetic.

5. Peeling off the self-adhesive drapes gently and slowly, optimally with the patient's attention distracted through a conversation.

\section{Data Sharing Statement}

Readers can access the data supporting the conclusions of the study upon e-mail requests from the corresponding author. The names and personal data of the participants could not be released due to ethical considerations.

\section{Author Contributions}

IO worked on the main text, analyzed, and interpreted the data. DŁ collected data from patients. ZM reviewed the entire article. JK worked in the main text. All authors made substantial contributions to conception and design, acquisition of data, or analysis and interpretation of data; took part in drafting the article or revising it critically for important intellectual content; agreed to submit to the current journal; gave final approval of the version to be published; and agree to be accountable for all aspects of the work. 


\section{Funding}

This research did not receive any specific grant from funding agencies in the public, commercial, or not-forprofit sectors, or any other financial support. This study was performed as part of the employment of the authors at the Medical University of Bialystok, Poland.

\section{Disclosure}

The authors report no conflicts of interest in this work.

\section{References}

1. Fagerström R. Fear of a cataract operation in aged persons. Psychol Rep. 1993;72:1339-1346. doi:10.2466/pr0.1993.72.3c.1339

2. Foggitt PS. Anxiety in cataract surgery: a pilot study. $J$ Cataract Refract Surg. 2001;27:1651-1655. doi:10.1016/S0886-3350(01)00859-8

3. Mitsonis CI, Mitropoulos PA, Dimopoulos NP, et al. Anxiety and depression in cataract surgery: a pilot study in the elderly. Psychol Rep. 2006;99:257-265. doi:10.2466/pr0.99.1.257-265

4. Marback R, Temporini E, Kara-Junior N. Emotional factors prior to cataract surgery. Clinics. 2007;62:433-438. doi:10.1590/S180759322007000400010

5. Ramirez DA, Brodie FL, Rose-Nussbaumer J, Ramanathan S. Anxiety in patients undergoing cataract surgery: a pre- and postoperative comparison. Clin Ophthalmol. 2017;11:1979-1986. doi:10.2147/OPTH.S146135

6. Ługowska D, Konopińska J, Mariak Z, Obuchowska I. Comparison of subjective preoperative experiences of patients before first- or second-eye cataract surgeries. Clin Ophthalmol. 2020;14:2883-2889. doi:10.2147/OPTH.S270196

7. Nijkamp MD, Kenens CA, Dijker AJM, Ruiter RAC, Hiddema F, Nuijts RMMA. Determinants of surgery related anxiety in cataract patients. $B r \quad J$ Ophthalmol. 2004;88:1310-1314. doi:10.1136/ bjo. 2003.037788

8. Morrell G. Effect of structured preoperative teaching on anxiety levels of patients scheduled for cataract surgery. Insight. 2001;26:4-9. doi:10.1067/min.2001.113201

9. Kowalczuk K, Cybulski M, Cybulski Ł, Krajewska-Kułak E. Pain perception and acceptance of illness in patients undergoing phacoemulsification cataract surgery under drip anesthesia. J Clin Med. 2019;8:1575. doi:10.3390/jcm8101575

10. Biró Z, Schvöller M. Subjective visual sensations during cataract surgery performed under topical anaesthesia. Acta Ophthalmol. 2008;86:894-896. doi:10.1111/j.1755-3768.2007.01153.x

11. Newman DK. Visual experience during phacoemulsification cataract surgery under topical anaesthesia. Br J Ophthalmol. 2000;84:13-15. doi:10.1136/bjo.84.1.13

12. Au Eong KG, Low $\mathrm{CH}$, Heng WJ, et al. Subjective visual experience during phacoemulsification and intraocular lens implantation under topical anesthesia. Ophthalmology. 2000;107:248-250. doi:10.1016/ S0161-6420(99)00080-9

13. Rengaraj V, Radhakrishnan M, Au Eong KG, et al. Visual experience during phacoemulsification under topical versus retrobulbar anesthesia: results of a prospective, randomized, controlled trial. Am J Ophthalmol. 2004;138:782-787. doi:10.1016/j.ajo.2004.06.023

14. Verma D. Subjective visual experience during phacoemulsification and intraocular lens implantation under topical anesthesia. Ophthalmology. 2001;108:1004-1005. doi:10.1016/S0161-6420(00) 00424-3

15. Wenzel M, Schulze Schwering M. Which colours are seen by the patient during cataract surgery? Results of an intraoperative interview. Eye. 2016;30(3):385-391. doi:10.1038/eye.2015.239
16. Rothschild PR, Grabar S, Le Dû B, Temstet C, Rostaqui O, Brézin AP. Patients' subjective assessment of the duration of cataract surgery: a case series. BMJ Open. 2013;3(5):e002497. doi:10.1136/ bmjopen-2012-002497

17. Chaudhry TA, Aqil A, Aziz K, Javed AA, Tauqir MZ, Ahmad K. Patients' visual experience during phacoemulsification cataract surgery and associated fear. BMC Res Notes. 2014;7(1):663. doi:10.1186/1756-0500-7-663

18. Haripriya A, Tan CSH, Venkatesh R, Aravind S, Dev A, Au Eong KG. Effect of preoperative counseling on fear from visual sensations during phacoemulsifications under topical anesthesia. $J$ Cataract Refract Surg. 2011;37:814-818. doi:10.1016/j. jcrs.2010.11.041

19. Voon LW, Au Eong KG, Saw SM, Verma D, Laude A. Effect of preoperative counseling on patient fear from the visual experience during phacoemulsifications under topical anesthesia: multicenter randomized clinical trial. $J$ Cataract Refract Surg. 2005;31:1966-1969. doi:10.1016/j.jcrs.2005.03.059

20. Adatia FA, Munro M, Jivraj I, Ajani A, Braga-Mele R. Documenting the subjective patients experience of first versus second cataract surgery. J Cataract Refract Surg. 2015;41(1):116-121. doi:10.1016/ j.jcrs.2014.04.041

21. Yu J, Ye T, Huang Q, et al. Comparison between subjective sensations during first and second phacoemulsification eye surgeries in patients with bilateral cataract. $J$ Ophthalmol. 2016;6521567. doi:10.1155/2016/6521567

22. Aslan L, Aslankurt M, Cekic O, Aksoy A, Yildiz H. The pain experience and cooperation of patients in consecutive cataract surgery. Eur J Ophthalmol. 2013;23(3):339-343. doi:10.5301/ ejo.5000219

23. Shi C, Yuan J, Zee B. Pain perception of the first eye versus the second eye during phacoemulsification under local anesthesia for patients going through cataract surgery: a systematic review and meta-analysis. $J$ Ophthalmol. 2019;4106893. doi:10.1155/2019/ 4106893

24. Liu P, Zhang S, Geng Z, Yuan R, Jian Y. Factors affecting pain in patients undergoing bilateral cataract surgery. Int Ophthalmol. 2020;40(2):297-303. doi:10.1007/s10792-019-01178-6

25. Akkaya S, Özkurt YB, Aksoy S, Kökcen HK. Differences in pain experience and cooperation between consecutive surgeries in patients undergoing phacoemulsification. Int Ophthalmol. 2017;37 (3):545-552. doi:10.1007/s10792-016-0295-3

26. Panagiotopoulou EK, Ntonti P, Vlachou E, Georgantzoglou K, Labiris G. Patients' expectations in lens extraction surgery: a systematic review. Acta Med. 2018;61:115-124. doi:10.14712/ 18059694.2018.129

27. Pager CK. Expectations and outcome in cataract surgery: a prospective test of 2 models of satisfaction. Arch Ophthalmol. 2004;122(12):1788-1792. doi:10.1001/archopht.122.12.1788

28. Pager CK. Randomised controlled trial of preoperative information to improve satisfaction with cataract surgery. Br J Ophthalmol. 2005;89 (1):10-13. doi:10.1136/bjo.2004.048637

29. Nijkamp MD, Ruiter RAC, Roeling M, et al. Factors related to fear in patients undergoing cataract surgery: a qualitative study focusing factors associated with the fear and reassurance among patients who need to undergo cataract surgery. Patient Educ Couns. 2002;47:265-272. doi:10.1016/S0738-3991(02)00002-2

30. Addisu Z, Solomon B. Patients' preoperative expectation and outcome of cataract surgery at Jimma University Specialized HospitalDepartment of Ophthalmology. Ethiop J Health Sci. 2011;21 (1):47-55. doi:10.4314/ejhs.v21i1.69044

31. Chen Z, Lin X, Qu B, et al. Preoperative expectations and postoperative outcomes of visual functioning among cataract patients in Urban Southern China. PLoS One. 2017;12(1):e0169844. doi:10.1371/journal.pone.0169844 
32. Hawker MJ, Madge SN, Baddeley PA, Perry SR. Refractive expectations of patients having cataract surgery. J Cataract Refract Surg. 2005;31(10):1970-1975. doi:10.1016/j.jcrs.2005.03.065

33. Kara-Júnior N, Temporini ER, Kara-José N. Cataract surgery: expectations of patients assisted during a community project in San Paulo, state of Sao Paulo, Brazil. Rev Hosp Clin Fac Med Sao Paulo. 2001;56(6):163-168. doi:10.1590/S0041-87812001000600001

34. Tielsch JM, Steinberg EP, Cassard SD, et al. Preoperative functional expectations and postoperative outcomes among patients undergoing first eye cataract surgery. Arch Ophthalmol. 1995;113 (10):1312-1318. doi:10.1001/archopht.1995.01100100100038

35. Mollazadegan K, Lundström M. A study of the correlation between patient-reported outcomes and clinical outcomes after cataract surgery in ophthalmic clinics. Acta Ophthalmol. 2015;93(3):293-298. doi:10.1111/aos. 12490

36. Nijkamp MD, Dolders MG, de Brabander J, van den Borne B, Hendrikse F, Nuijts RM. Effectiveness of multifocal intraocular lenses to correct presbyopia after cataract surgery: a randomized controlled trial. Ophthalmology. 2004;111(10):1832-1839. doi:10.1016/j.ophtha.2004.05.023
37. Gong DH, Liu JF, Zhao X, Zhang L. The effect of nursing intervention on preoperative cataract. Medicine. 2018;97(42):e12749. doi:10.1097/MD.0000000000012749

38. Özlü ZK, Tuğ O, Yayla AC. Inevitable problems of older people: presurgery information effect on anxiety levels in patients undergoing cataract surgery. $J$ Clin Nurs. 2016;25(9-10):1388-1394. doi:10.1111/jocn. 13233

39. Hardy J. Supporting patients undergoing cataract extraction surgery. Nurs Stand. 2009;24(14):51-56. doi:10.7748/ns.24.14.51.s48

40. Marsden J. Cataract: the role of nurses in diagnosis, surgery and aftercare. Nurs Times. 2004;100(7):36-40.

41. Dutt-Gupta J, Bown T, Cyna AM. Effect of communication on pain during intravenous cannulation: a randomized controlled trial. $\mathrm{Br}$ J Anaesth. 2007;99(6):871-875. doi:10.1093/bja/aem308

42. van Loon H, Puijn F, van Aarle LA, van Daele WH, Bouwman ATD. Pain upon inserting a peripheral intravenous catheter: size does not matter. J Vasc Access. 2018;19(3):258-265. doi:10.1177/ 1129729817747531
Clinical Ophthalmology

\section{Publish your work in this journal}

Clinical Ophthalmology is an international, peer-reviewed journal covering all subspecialties within ophthalmology. Key topics include: Optometry; Visual science; Pharmacology and drug therapy in eye diseases; Basic Sciences; Primary and Secondary eye care; Patient Safety and Quality of Care Improvements. This journal is indexed on PubMed
Dovepress

Central and CAS, and is the official journal of The Society of Clinical Ophthalmology (SCO). The manuscript management system is completely online and includes a very quick and fair peer-review system, which is all easy to use. Visit http://www.dovepress.com/ testimonials.php to read real quotes from published authors. 